\title{
Network meta-analysis of success rate and safety in antibiotic treatments of bronchitis
}

\author{
This article was published in the following Dove Press journal: \\ International Journal of COPD \\ 9 August 2017 \\ Number of times this article has been viewed
}

\author{
Jinghua Wang' \\ Haiyang $\mathrm{Xu}^{2}$ \\ Pan Liu $^{3}$ \\ Mingxian $\mathrm{Li}^{4}$ \\ 'Pediatric of Rheumatology, \\ Immunology and Allergy, The First \\ Hospital of Jilin University, Changchun, \\ ${ }^{2}$ Department of Anesthesiology, The \\ First Hospital of Jilin University, \\ Changchun, ${ }^{3}$ Department of Oncology, \\ The First Affiliated Hospital of \\ Xinjiang Medical University, Urumqi, \\ ${ }^{4}$ Department of Respiratory, The \\ First Hospital of Jilin University, \\ Changchun, China
}

\begin{abstract}
The purpose of this study was to compare the relative efficacy and safety of different antibiotic drugs and recommend superior regimens in the treatment of bronchitis. With respect to the antibiotic comparisons against quinolones in terms of intention-to-treat patients, we concluded that quinolones had advantages over placebo, $\beta$-lactams, sulfonamides, and double $\beta$-lactams. Concerning treatment methods for clinically evaluable patients, quinolones demonstrated better performance than $\beta$-lactams and sulfonamides. The secondary effects of macrolides, quinolones, and double $\beta$-lactams were significantly more adverse than $\beta$-lactams with odds ratios (ORs) of $1.5(95 \%$ credible interval $[\mathrm{CrI}]=1.1-2.0), 1.7(95 \% \mathrm{CrI}=1.2-2.3)$, and $2.7(95 \% \mathrm{CrI}=1.8-4.1)$, respectively. Significant differences in the prevalence of diarrhea as a secondary effect were only identified among the comparisons of double $\beta$-lactams against $\beta$-lactams and macrolides ( $\mathrm{OR}=5.0,95 \% \mathrm{CrI}=2.1-12.0 ; \mathrm{OR}=3.0,95 \% \mathrm{CrI}=1.7-5.4$, respectively). Quinolones can be recommended as the superior treatment for bronchitis, in accordance with our cluster analysis with surface under the cumulative ranking curve. The primary outcomes of network metaanalysis indicated that quinolones showed the best performance among the 8 treatments studied, although $\beta$-lactams showed the lowest risk of adverse side effects. Quinolones are recommended as the primary treatment option for bronchitis patients, having taking into account the success rates and safety profiles of the eight drugs studied here.
\end{abstract}

Keywords: bronchitis, antibiotic treatments, success rate, safety, network meta-analysis

\section{Introduction}

Bronchitis is a disease commonly caused by bacteria ${ }^{1}$ like Streptococcus pneumoniae, Haemophilus influenzae, and Moraxella catarrhalis ${ }^{2}$ as well as by viruses. ${ }^{3}$ Acute bronchitis (AB), chronic bronchitis (CB), and acute exacerbations of chronic bronchitis (AECB) are the three main types of bronchitis. Patients usually experience symptoms such as coughing, wheezing dyspnea, greater sputum volume, rales, and rhonchi. ${ }^{4}$ The illness is a major public health concern, due to its remarkably high morbidity rate. Also of concern, the disease can induce long-term effects such as a decline in lung function and a higher risk of cardiovascular disease..$^{5-10}$ Thus, the morbidity rate and severe health conditions caused by bronchitis constitute a serious burden for the modern health care system.

This disease has been studied for a long time, and various types of drugs have been developed or identified for the treatment of bronchitis including mucolytics and antibiotics; however, antibiotics have been used more commonly than mucolytics in both clinical trials and treatment of bacterial bronchitis. It has been noted that the administration of antibiotics is currently regarded as a considerable step in the treatment of AECB. ${ }^{11}$ In addition, antibiotics have shown superior efficacy in their ability to reduce cardinal symptoms compared to other type of intervention. ${ }^{12}$
Department of Respiratory, The First Hospital of Jilin University, No 7 I Xinmin Street, Changchun I3002 I, Jilin, China $\mathrm{Tel} / \mathrm{fax}+8643188782319$

Email zmkt_z@163.com 
For instance, AECB patients are commonly treated with many oral agents that actively act as antibacterials against pathogens, including fluoroquinolone, $\beta$-lactam, tetracycline, macrolide, or trimethoprim-sulfamethoxazole. ${ }^{2}$ To the best of our knowledge, there are seven major groups of antibiotic treatments available in the treatment of bronchitis: $\beta$-lactams, macrolides, tetracyclines, quinolones, sulfonamides, double $\beta$-lactams, and double sulfonamides. The safety and tolerability profiles of tetracyclines, ${ }^{13}$ moxifloxacin, ${ }^{4,14-16}$ and clarithromycin ${ }^{17}$ strongly suggest that these are superior compared to other drugs when administered in the treatment of bronchitis-related symptoms. However, clinical trials have shown that the commonly used $\beta$-lactams drug, phenethicillin, has demonstrated little efficacy compared to placebo. ${ }^{18}$ Gemifloxacin, a type of quinolone with a powerful capacity in eliminating respiratory tract pathogens, enabled patients with AECB to remain recurrence-free after 26 weeks. ${ }^{19}$ Post-therapy cure rates among AECB patients treated with telithromycin and axetil were $86.4 \%$ and $83.1 \%$, respectively. ${ }^{2}$ These results suggest a strong efficacy with respect to the treatment of $\mathrm{AECB}$. Roxithromycin and doxycycline also displayed satisfactory outcomes, with clinical success rates of $81 \%$ and $80 \%$ and an adverse effect incidence rate of $12.2 \%$ and $33 \%$, respectively. It has been recommended that roxithromycin should be considered the preferred antibiotic treatment for bronchitis due to its efficacy and safety characteristics..$^{20}$ Other related studies ${ }^{17,21}$ have attempted to combine two or three different regimens, such as sulfadiazine and trimethoprim, to obtain a higher success rate. However, the overuse of various antibiotics in treating bacterial diseases including bronchitis has already led to a rise in antibiotic resistance worldwide. ${ }^{2}$ This indicates the need for a wiser regulation and selection process for the use of antibiotics in the treatment of bacterial diseases. More well-focused and safer regimens for bacterial infections are needed, as this will reduce the potential risk of causing multiple drug resistance strains.

As such, researchers have been attempting to identify the most suitable antibiotic drug for the treatment of bronchitis with the highest efficacy and fewest adverse effects. Several meta-analyses (MAs) have already provided us with clear insight into the comparative efficacy and safety of different antibiotics, such as amoxicillin, ${ }^{22}$ erythromycin, ${ }^{23}$ macrolides, ${ }^{24}$ quinolones, ${ }^{24}$ moxifloxacin, ${ }^{25,26}$ penicillins, ${ }^{27}$ and gemifloxacin ${ }^{28}$ through head-to-head comparison methods. Nevertheless, we still know little about the relative efficacy of other medical treatments used to treat bronchitis. Thus, the antibiotic family of treatment options is still not comprehensively understood, as it has not been compared to other families of treatment options. Aside from this, assessment results have even demonstrated significant heterogeneity among the same antibiotic drugs, which further complicates the drug selection process.

However, the shortcomings extant in current conventional MAs and individual studies may be made up for by conducting a network meta-analysis (NMA) which offers indirect evidences between different regimens based on direct evidence provided by clinical trials. This new statistical method is now applied frequently in the field of pharmaceutical screening and evaluation ${ }^{29-33}$ and has proven to be an effective way to recognize the overall superiority and inferiority of different interventions.

The objective of this work is to compare the relative efficacy and safety of different antibiotic drugs and recommend superior regimens in the treatment of bronchitis, especially bacteria-induced bronchitis. It is hoped that the results of this NMA will provide insight into efficient treatment options as well as help to avoid the misuse of less effective and more harmful antibiotics. As far as we know, this is also the first NMA conducted on bronchitis-targeted antibiotic interventions.

\section{Methods \\ Database and search strategies}

We searched China National Knowledge Internet, PubMed, and Embase for relevant articles up to April 10, 2016, without restrictions on language. Keywords such as "bronchitis," "anti-bacterial agents," "quinolones," "betalactams," "macrolides," "mucolytics," "expectorants," and "trimethoprim" as well as their correlated expressions were included in our search strategy. The reference lists of all retrieved articles were also reviewed manually to identify any relevant studies that may have been overlooked. Parallel literature screenings were carried out by two reviewers independently.

\section{Inclusion criteria}

All included articles met the following criteria: 1) randomized controlled trials (RCTs); 2) sufficient relevant data existed concerning the outcomes (the intention-to-treat [ITT] patients' treatment success rate, clinically evaluable (CE) patients' treatment success rate, adverse effects, and diarrhea); and 3) patients were diagnosed with bronchitis for at least three consecutive months or had a history of bronchitis.

\section{Data extraction}

Two investigators independently extracted relevant data from the included articles, including the name of the experiment 
conductor(s), year of publication, sample size, age and conditions of sample subjects, dose and duration of treatment, and the drugs used in the treatment. Any disagreements between the two investigators were subject to a third party discussion until a consensus was established.

\section{Statistical analysis}

This NMA was carried out with a random-effects model of Bayesian framework analysis using WinBUGS (V1.4.3, University of Cambridge) and R software (V3.3.1). ORs and their $95 \%$ credible intervals (95\% CrIs) were applied for comparisons between two target therapies on each outcome. Node splitting plots were constructed to show the consistency and inconsistency between direct and indirect evidence. A $P$-value of $<0.05$ indicated a significant difference. Heat plots were also graphed to better demonstrate the heterogeneity level. A warmer color indicated stronger heterogeneity concerning the relevant comparison. In addition, the surface under the cumulative ranking curve (SUCRA) was calculated to rank each therapy on 4 outcomes, including ITT patient treatment success rate, CE patient treatment success rate, adverse effects, and diarrhea. A higher SUCRA value corresponds to a higher level of efficiency and safety. Finally, cluster plots were drawn to make the process of choosing the most appropriate therapy more efficient.

\section{Results}

\section{Basic characteristics of eligible studies}

A total of 1,160 studies were identified by using the search strategies detailed above. Finally, 48 eligible studies were selected for data extraction. The literature screening process is shown in Figure 1. Initially, 346 studies were categorized as ineligible due to duplication. Out of 814 full-text articles, we identified 86 and rejected the others due to irrelevant treatment, outcome data, comparison, or not being RCT studies. Finally, only 48 of the 86 articles, with a total of 14,448 participants were retrieved.,2,12-21,34-69 Among the 48 studies, 29 of the randomized trials were double blind, 5 were single blind, and the others were open-label or unspecified. The most popular treatments assessed were quinolones and macrolides. Other relevant characteristics of these studies are shown in Table 1.

\section{NMA results of ITT patient treatment success and $C E$ patient treatment success rates}

Figure 2 shows the network comparisons between placebo and antibiotics on ITT patient treatment success rates and
Studies identified through searching PubMed and Embase $(n=1,160)$

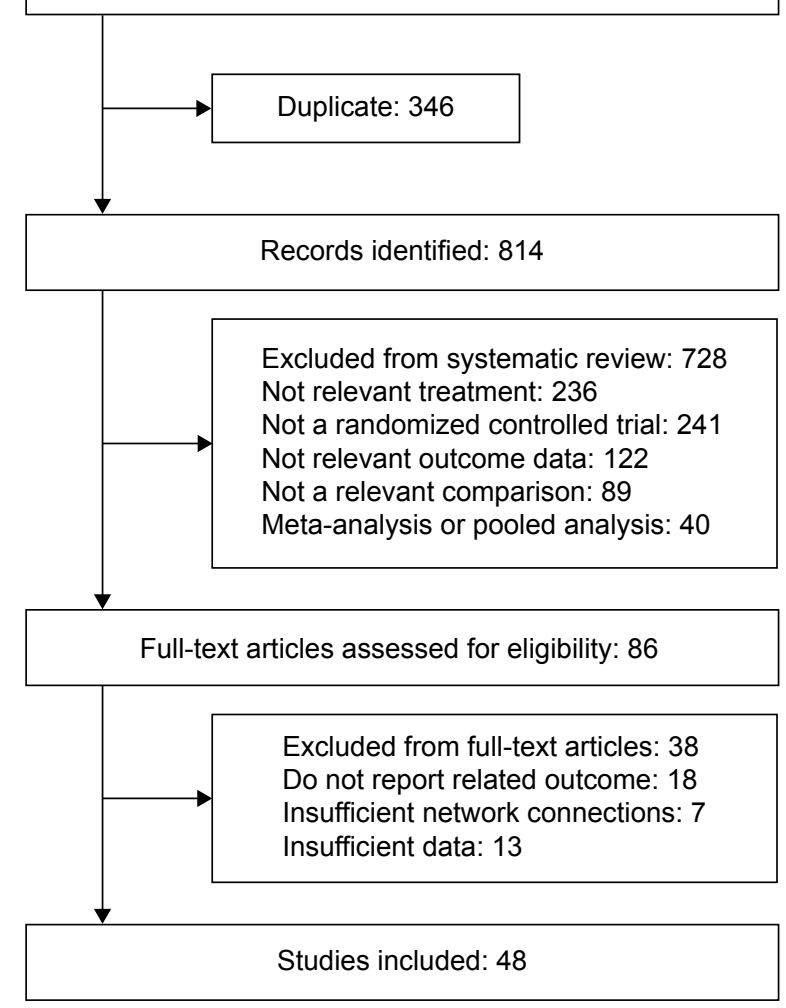

Figure I Flow diagram of literature search.

CE patient treatment success rates. Adverse effects including diarrhea are shown in Figure 3.

As illustrated in Figure 2, $\beta$-lactams, macrolides, quinolones, sulfonamides, double $\beta$-lactams, and double sulfonamides were all more successful than placebo in treating ITT patients. From comparisons between quinolones and other treatments, we could conclude that quinolones had an advantage over placebo $(\mathrm{OR}=35.0,95 \% \mathrm{CrI}=5.2-$ 300.0), $\beta$-lactams (OR =1.6, 95\% CrI =1.1-2.4), sulfonamides $(\mathrm{OR}=8.3,95 \% \mathrm{CrI}=1.3-71.4)$, and double $\beta$-lactams (OR $=1.4,95 \% \mathrm{CrI}=1.0-2.0)$. Aside from this, sulfonamides seemed to be significantly less efficient than macrolides (OR $=0.13,95 \% \mathrm{CrI}=0.016-0.8)$.

We detected no significant difference between the effectiveness of placebo and antibiotics on CE patients. However, $\beta$-lactams demonstrated statistically lower efficacy when compared with quinolones and double $\beta$-lactams $(\mathrm{OR}=1.8$, 95\% CrI =1.2-2.8; OR =1.8, 95\% CrI =1.1-3.2), while sulfonamides showed less overall benefits than $\beta$-lactams (OR $=0.09,95 \% \mathrm{CrI}=0.003-0.97)$. Sulfonamides were also inferior to macrolides and quinolones with ORs of 0.07 (95\% CrI $=0.002-0.76)$ and 0.05 (95\% CrI $=0.002-0.55)$, respectively. In addition, both double $\beta$-lactams and double 


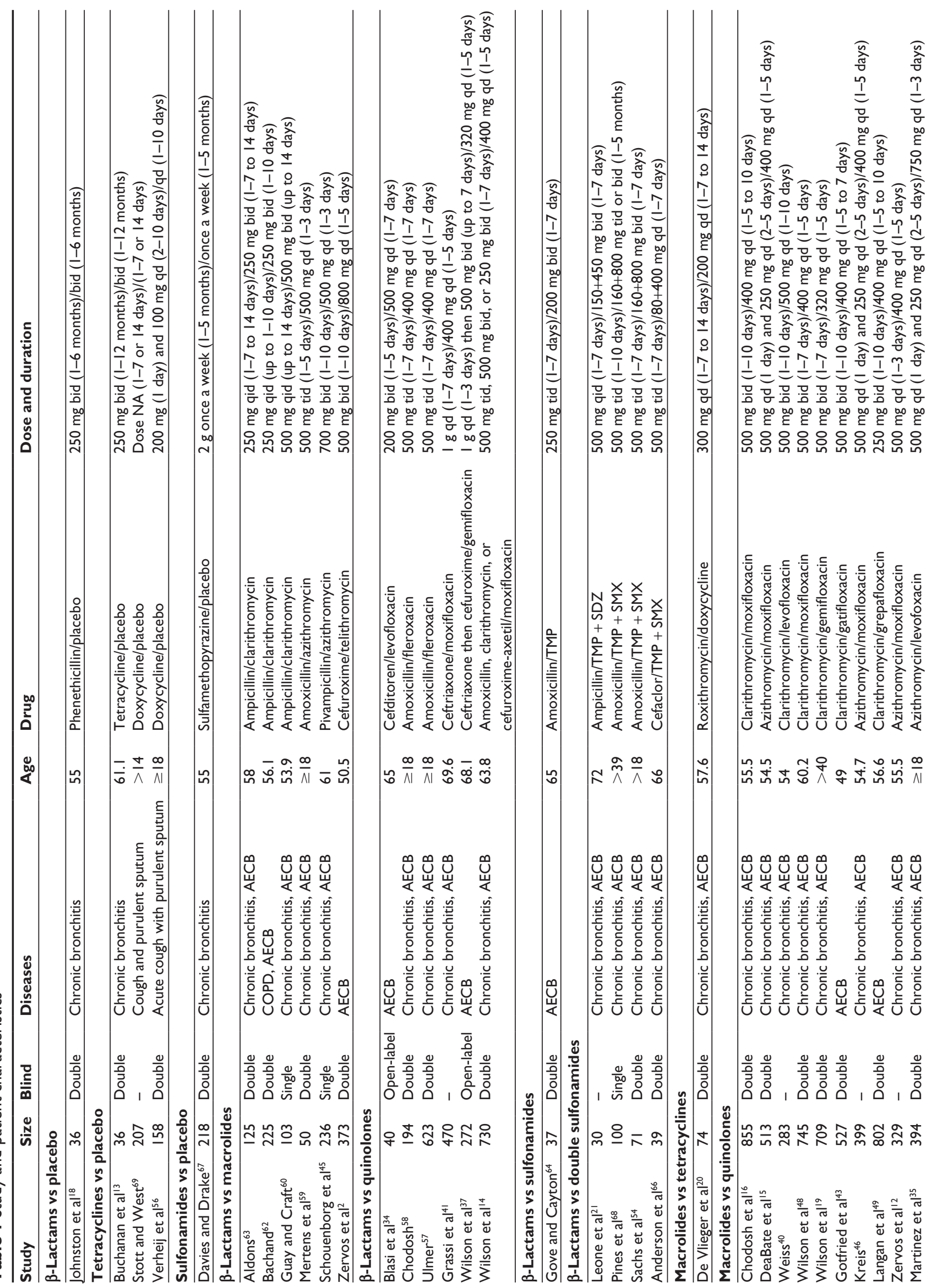




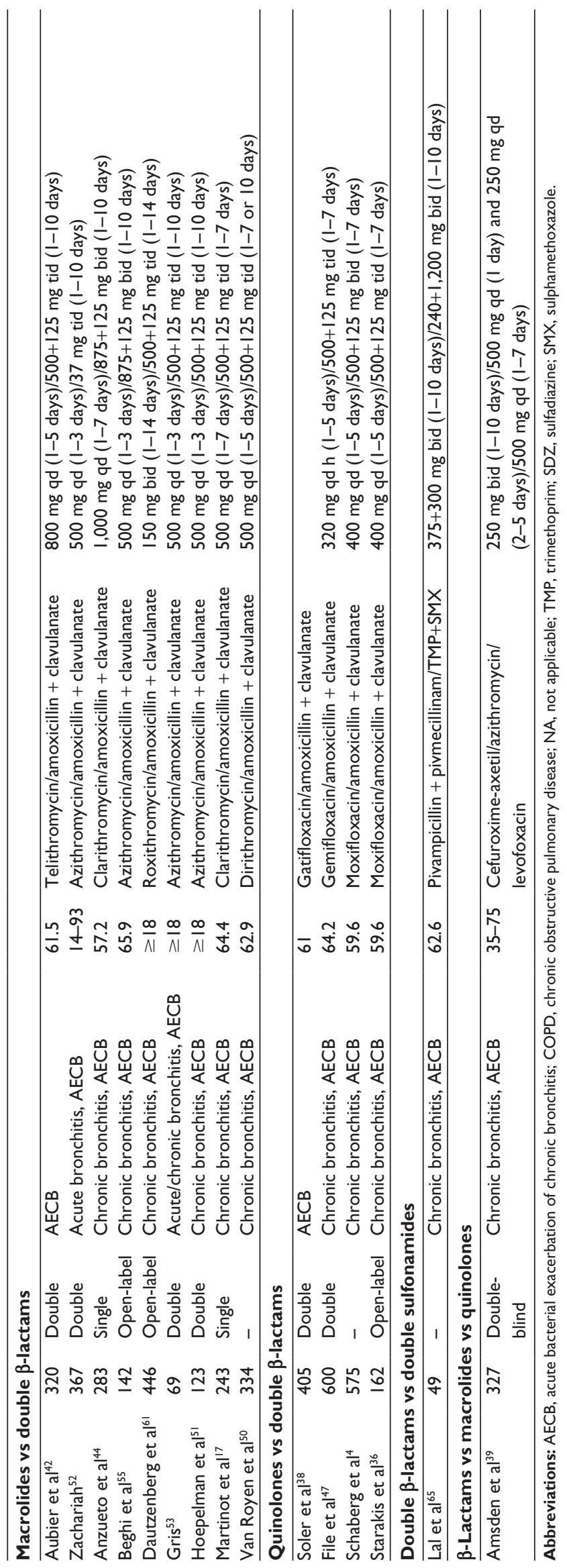

sulfonamides showed higher efficacy compared to sulfonamides ( $\mathrm{OR}=20.0,95 \% \mathrm{CrI}=1.7-640$; $\mathrm{OR}=16.0$, $95 \% \mathrm{CrI}=1.2-560$, respectively). This suggested to us that quinolones and macrolides were a suitable treatment option for ITT bronchitis patients, while quinolones and double $\beta$-lactams proved superior to other antibiotics as a treatment option in $\mathrm{CE}$ bronchitis patients.

\section{NMA results of all adverse effects and diarrhea}

As to the secondary outcomes of all adverse effects shown in Figure 3, macrolides, quinolones, and double $\beta$-lactams were three drugs which showed significantly higher risk of inducing adverse effects compared to $\beta$-lactams $(\mathrm{OR}=1.5$, $95 \% \mathrm{CrI}=1.1-2.0 ; \mathrm{OR}=1.7,95 \% \mathrm{CrI}=1.2-2.3 ; \mathrm{OR}=2.7$, $95 \% \mathrm{CrI}=1.8-4.1)$. In addition, double $\beta$-lactams were more harmful than macrolides and quinolones with ORs of 1.8 $(95 \% \mathrm{CrI}=1.4-2.5)$ and $1.6(95 \% \mathrm{CrI}=1.2-2.2)$, respectively.

Figure 3 also offers evidence concerning diarrhea as an adverse effect. We did not conduct a study on diarrhea as a side effect of sulfonamides due to a lack of data. The only significant differences were identified in the comparisons of double $\beta$-lactams against $\beta$-lactams and macrolides $(\mathrm{OR}=5.0$, $95 \% \mathrm{CrI}=2.1-12.0 ; \mathrm{OR}=3.0,95 \% \mathrm{CrI}=1.7-5.4$, respectively). Based on the above safety findings, $\beta$-lactams seemed to be the most tolerable therapy as it was the least likely to induce adverse effects including diarrhea. When adverse effects were taken into consideration, double $\beta$-lactams seems to be the therapy with the worst adverse effects in bronchitis.

\section{Consistency assessments}

In this study, node splitting plots (Figure 4) and net heat plots (Figure 5) were used to assess the consistency level between direct and indirect evidence. No significant discrepancy was found between direct and indirect evidence on ITT patient treatment success rates and CE patient treatment success rates. However, there was inconsistency in the comparison between direct and indirect evidence from quinolones versus $\beta$-lactams, quinolones versus macrolides, and macrolides versus $\beta$-lactams. Their associated $P$-values of adverse effects and diarrhea were $<0.05$, as demonstrated in Figure 4 . The red blocks shown in Figure 5 also indicate that a strong inconsistency was detected in the above noted comparisons.

\section{Treatment rankings and cluster analysis with SUCRA}

SUCRA rankings of each therapy on 4 indexes are demonstrated in Figure 6 and Table 2. First, quinolones and 


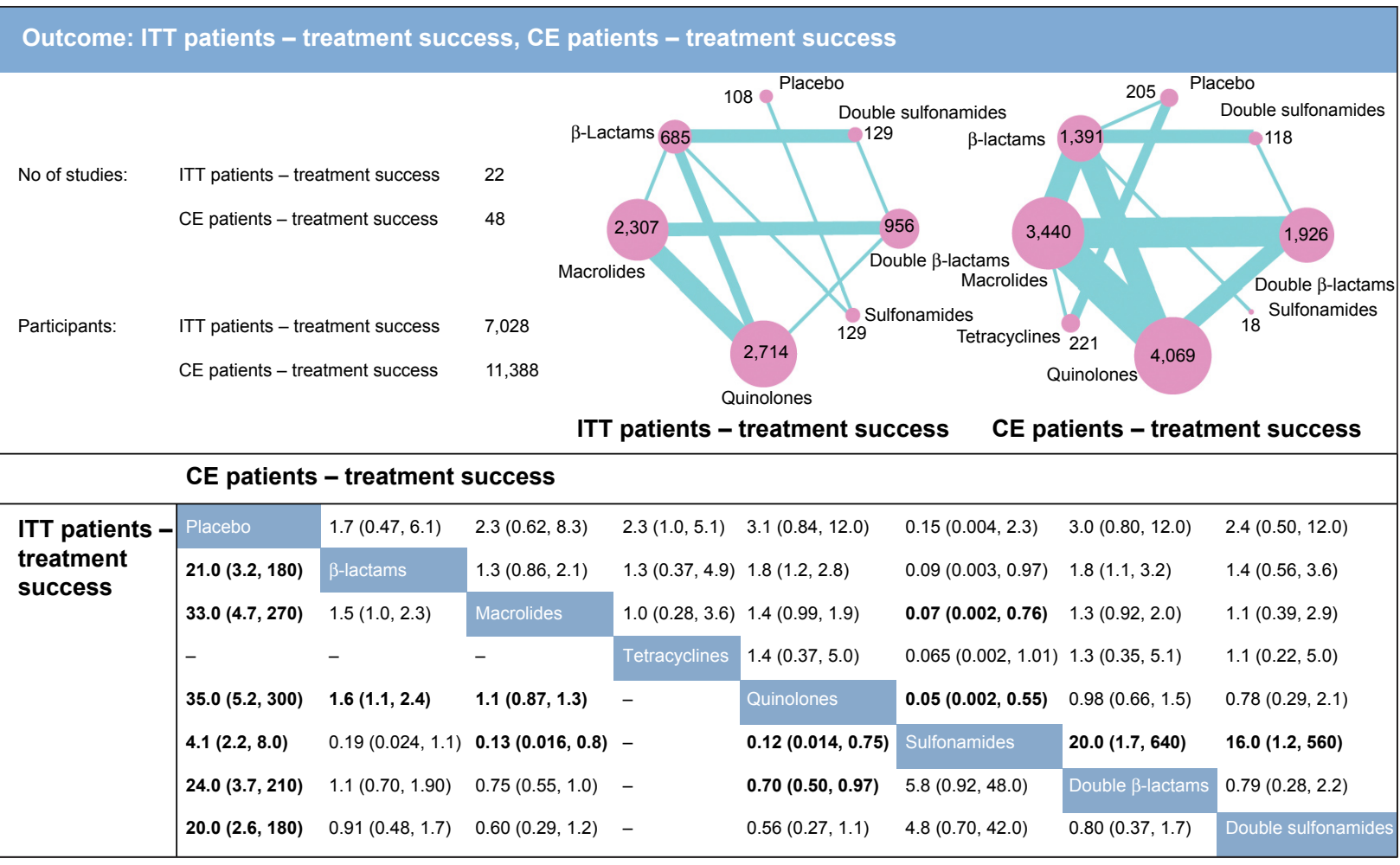

Figure 2 Network meta-analysis results for the endpoints of ITT patient treatment success and CE patient treatment success rates. The network plots show direct comparison of different therapies, with node size corresponding to sample size. The number of included studies for specific direct comparison governs the thickness of solid lines. ORs with $95 \% \mathrm{Crls}$ are applied to evaluate the efficacy outcomes. Note that in the upper half of the table, column treatments are compared against row treatments, whereas in the lower half of the table, row treatments are compared against column treatments. Bold data represents significant results.

Abbreviations: ITT, intention-to-treat; $\mathrm{CE}$, clinically evaluable; OR, odds ratio; $\mathrm{Crl}$, credible interval.

\begin{tabular}{|c|c|c|c|c|c|c|c|c|}
\hline \multicolumn{9}{|c|}{ Outcomes: adverse effects, diarrhea } \\
\hline $\begin{array}{l}\text { No of studies: } \\
\text { Participants: }\end{array}$ & $\begin{array}{l}\text { Adverse effects } \\
\text { Diarrhea } \\
\text { Adverse effects } \\
\text { Diarrhea }\end{array}$ & $\begin{array}{l}13,375 \\
11,123\end{array}$ & $\begin{array}{r}\beta \text {-Lactams 1,87 } \\
\text { Macrolides } \\
104,857 \\
\text { Tetracyclines } \\
\text { Quinolor }\end{array}$ & nes & $\begin{array}{l}\text { Double } \\
\text { sulfonamides }\end{array}$ & $\begin{array}{r}\beta \text {-Lactar } \\
3 \\
3 \\
\text { Macrolid } \\
1 \\
\text { Tetrac }\end{array}$ & $\begin{array}{ll}\text { Qyclines } & 4,489 \\
\text { Quinolones }\end{array}$ & $\begin{array}{l}95 \text { Double } \\
\text { sulfonamides } \\
1,768 \\
\text { Double } \\
\beta \text {-lactams }\end{array}$ \\
\hline & \multicolumn{8}{|l|}{ Diarrhea } \\
\hline \multirow{8}{*}{$\begin{array}{l}\text { Adverse } \\
\text { effects }\end{array}$} & Placebo & $0.97(0.019,50.0)$ & $1.6(0.029,88.0)$ & $1.3(0.26,6.0)$ & $1.5(0.027,82.0)$ & - & $4.9(0.086,260)$ & $2.2(0.031,170)$ \\
\hline & $0.9(0.22,4.0)$ & $\beta$-Lactams & $1.6(0.82,3.5)$ & $1.3(0.02,86.0)$ & $1.6(0.76,3.4)$ & - & $5.0(2.1,12.0)$ & $2.2(0.35,6.0)$ \\
\hline & $1.4(0.32,5.8)$ & $1.5(1.1,2.0)$ & Macrolides & $0.78(0.011,57.0)$ & $0.94(0.59,1.5)$ & - & $3.0(1.7,5.4)$ & $1.4(0.20,10.0)$ \\
\hline & $2.3(0.79,7.1)$ & $2.5(0.67,9.5)$ & $1.7(0.47,6.3)$ & Tetracyclines & $1.2(0.016,87.0)$ & - & $3.9(0.05,290)$ & $1.7(0.02,180)$ \\
\hline & $1.5(0.36,6.7)$ & $1.7(1.2,2.3)$ & $1.1(0.89,1.4)$ & $0.66(0.18,2.5)$ & Quinolones & - & $3.9(0.05,290)$ & $1.7(0.02,180)$ \\
\hline & $1.3(0.36,5.1)$ & $1.4(0.24,8.7)$ & $0.98(0.16,5.9)$ & $0.57(0.11,3.0)$ & $0.86(0.14,5.2)$ & Sulfonamides & - & - \\
\hline & $2.5(0.58,11.0)$ & $2.7(1.8,4.1)$ & $1.8(1.4,2.5)$ & $1.1(0.28,4.1)$ & $1.6(1.2,2.2)$ & $1.9(0.31,12.0)$ & Double $\beta$-lactams & $0.45(0.064,3.4)$ \\
\hline & $3.1(0.46,24.0)$ & $3.4(0.93,15.0)$ & $2.3(0.61,10.0)$ & $1.4(0.21,9.5)$ & $2.0(0.54,9.1)$ & $2.4(0.26,25.0)$ & $1.2(0.33,5.7)$ & Double sulfonamides \\
\hline
\end{tabular}

Figure 3 Network meta-analysis results for the endpoints of adverse effects and diarrhea. The network plots show direct comparison of different therapies, with node size corresponding to sample size. The number of included studies for specific direct comparison governs the thickness of solid lines. ORs with $95 \%$ Crls are applied to evaluate the efficacy outcomes. Note that in the upper half of the table, column treatments are compared against row treatments, whereas in the lower half of the table, row treatments are compared against column treatments. Bold data represents significant results.

Abbreviations: OR, odds ratio; $\mathrm{Crl}$, credible interval. 
macrolides proved to be the top two most successful antibiotic treatments for ITT bronchitis patients. They were both associated with a medium risk of adverse effects including diarrhea, as indicated in Figure 7. Moreover, quinolones and double $\beta$-lactams were effective in treating $\mathrm{CE}$ bronchitis patients but double $\beta$-lactams seemed to pose the highest overall risk of inducing adverse effects including diarrhea, as illustrated in the cluster plots in Figure 7. $\beta$-Lactams ranked first in reducing both overall adverse effects and diarrhea. All in all, the ranking and cluster analyses suggest quinolones as the superior treatment for bronchitis among antibiotics, considering that it produced an even balance between efficacy and safety performance.

\section{Discussion}

\section{Primary outcomes}

Based on our findings, quinolones and macrolides had the highest patient success rates, thus are recommended as the two most efficient drugs in treating ITT patients. In the meantime, quinolones and double $\beta$-lactams showed significant advantages over other types of antibiotics in terms of $\mathrm{CE}$ patient success rate. It should be noted that quinolones are a

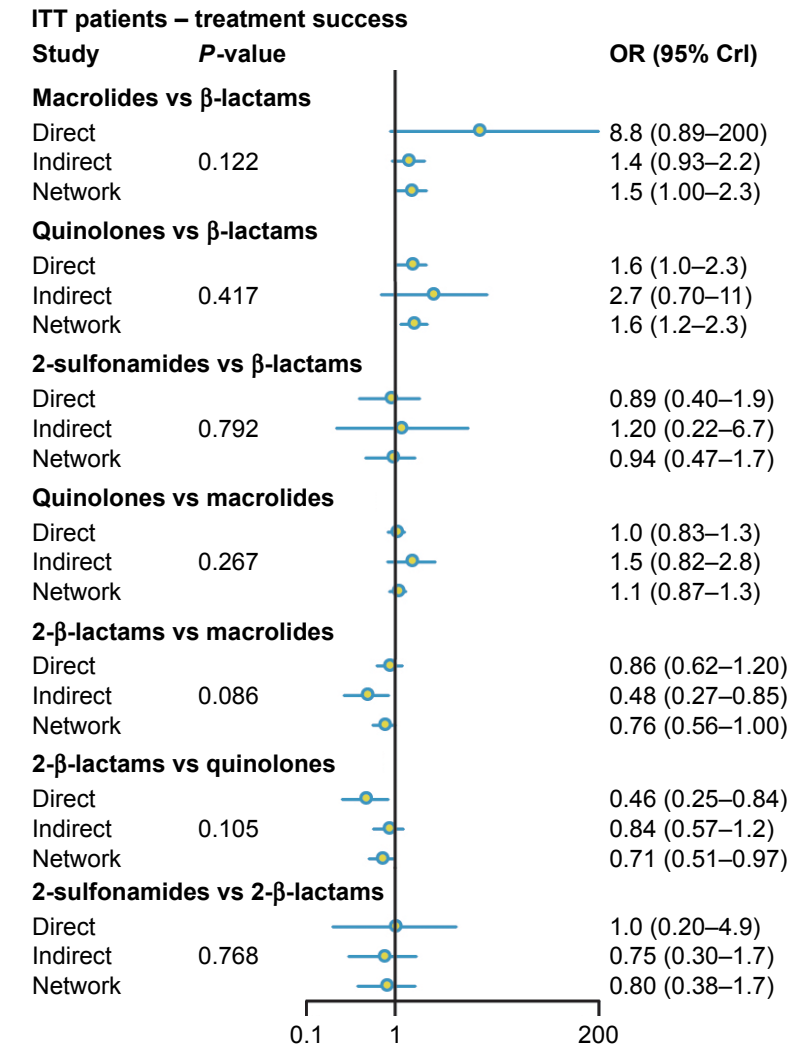

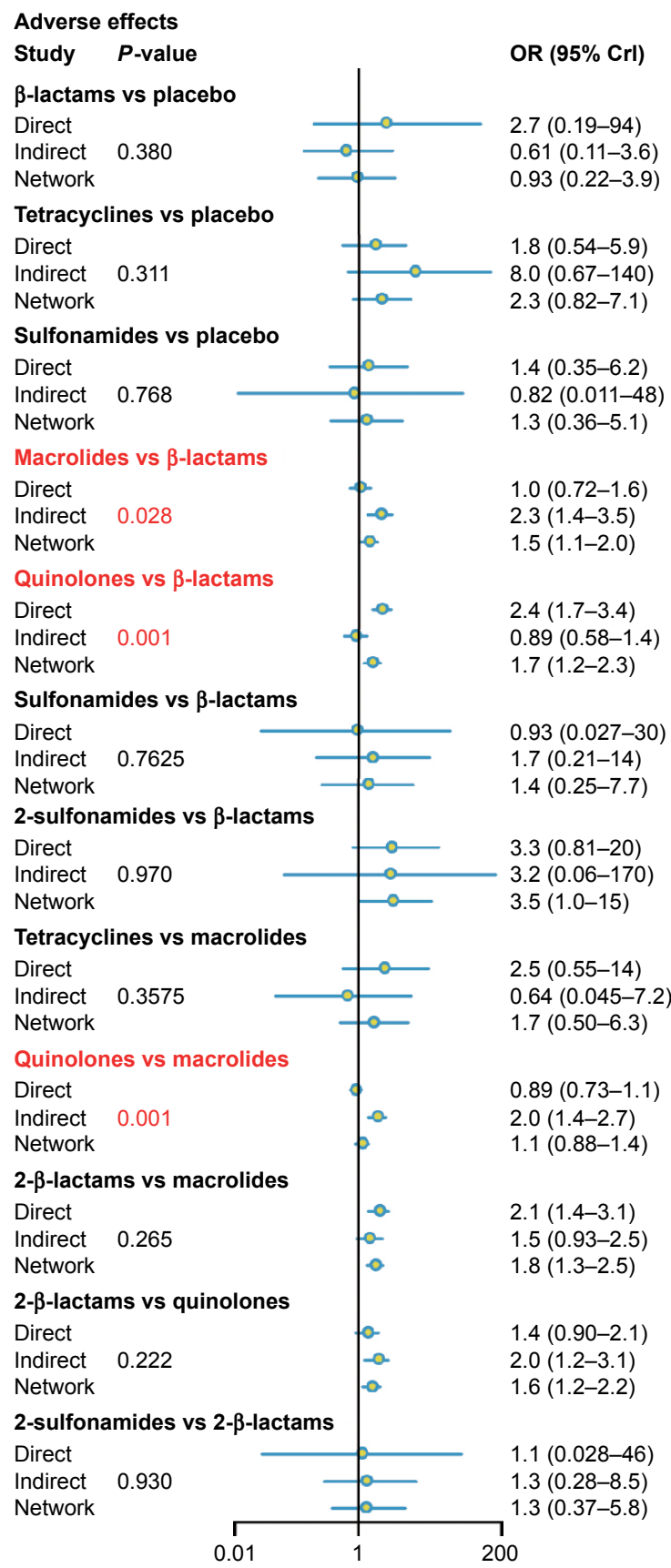

Figure 4 (Continued) 


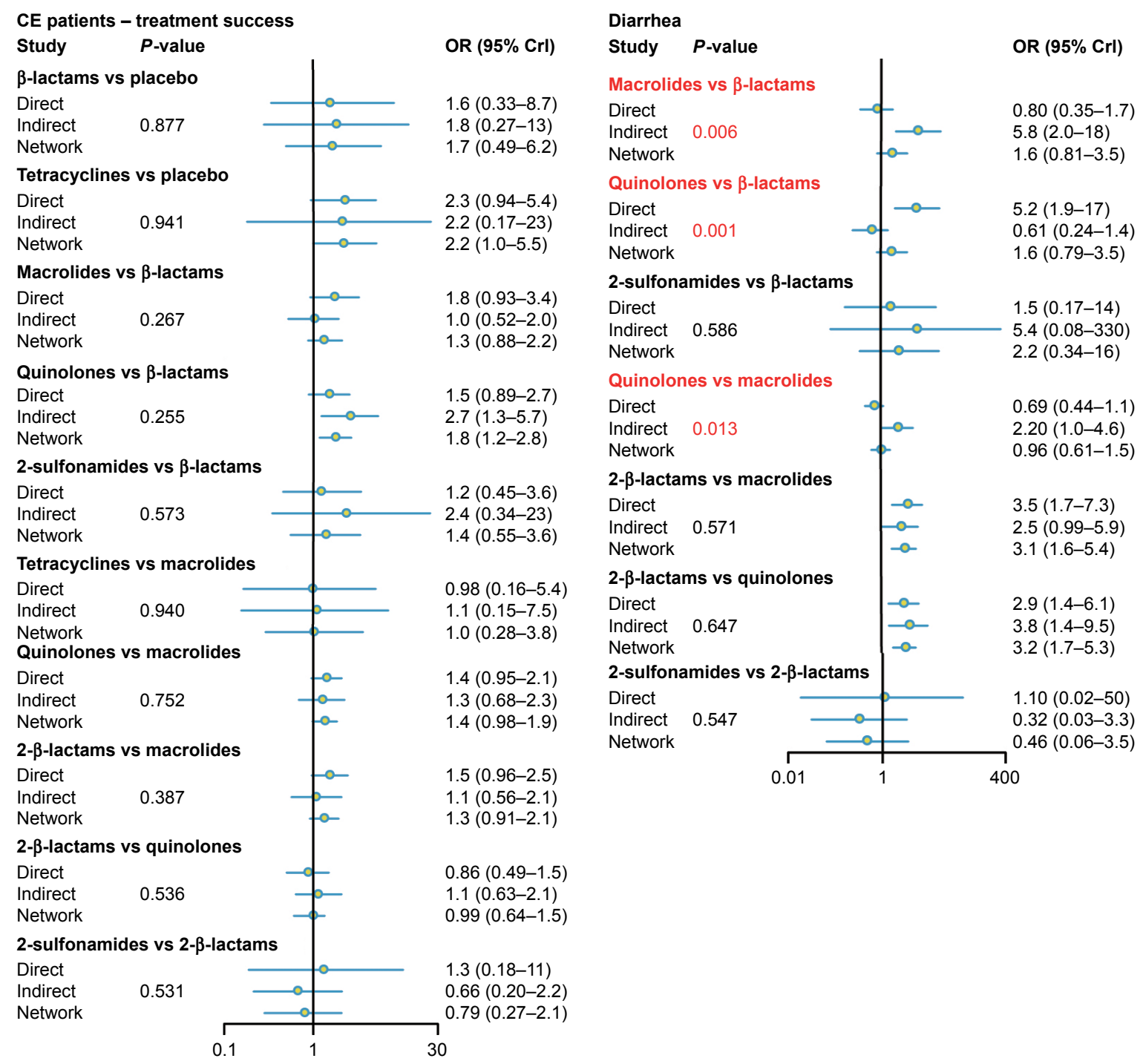

Figure 4 Node-splitting results for ITT patient treatment success, CE patient treatment success, adverse effects, and diarrhea. Abbreviations: ITT, intention-to-treat; CE, clinically evaluable; OR, odds ratio; Crl, credible interval.

family of synthetic broad-spectrum antibiotic drugs extracted from natural sources which function as antimicrobials. ${ }^{70,71}$ The core mechanism of their antibiotic ability is in preventing bacterial DNA from unwinding and duplicating, and thus, they have drastic effects on the reproduction cycles of bacteria cells. ${ }^{72}$

Macrolides have also been suggested as an effective treatment option for ITT bronchitis patients. This family of antibiotics also originates from natural products and can reduce the activity of bacteria by inhibiting the protein formation process of the bacteria. ${ }^{73,74}$ Double $\beta$-lactams are a combination of $\beta$-lactams, and moxicillin/clavulanate is the most commonly used combination. It was reported that combining two different $\beta$-lactams could produce a higher spectrum of action and efficacy compared to what is achievable with a single $\beta$-lactam treatment. ${ }^{22}$ This is also the reason for the inefficiency of some $\beta$-lactams in the treatment of bacteria-induced bronchitis.

The strong curative capacity of quinolones is displayed in various extant studies, showing that moxifloxacin, a quinolone, was superior to $\beta$-lactams ${ }^{14}$ and macrolides such as clarithromycin. ${ }^{16}$ An MA study targeting the treatment of oral gemifloxacin at $320 \mathrm{mg}$ daily for AECB patients also confirmed the superiority of quinolones compared to the other approved antibiotics tested. ${ }^{28}$ In another MA study by Siempos et al, ${ }^{24}$ quinolones was again proved to be more effective in removing bacteria than macrolides, which was consistent with our findings.

A similar level of efficacy was observed between macrolides and tetracyclines ${ }^{20}$ as well as between macrolides and double $\beta$-lactams s $^{17,24,42,44,52,61}$ on the basis of both clinical and MA studies. However, our study did show that macrolides 


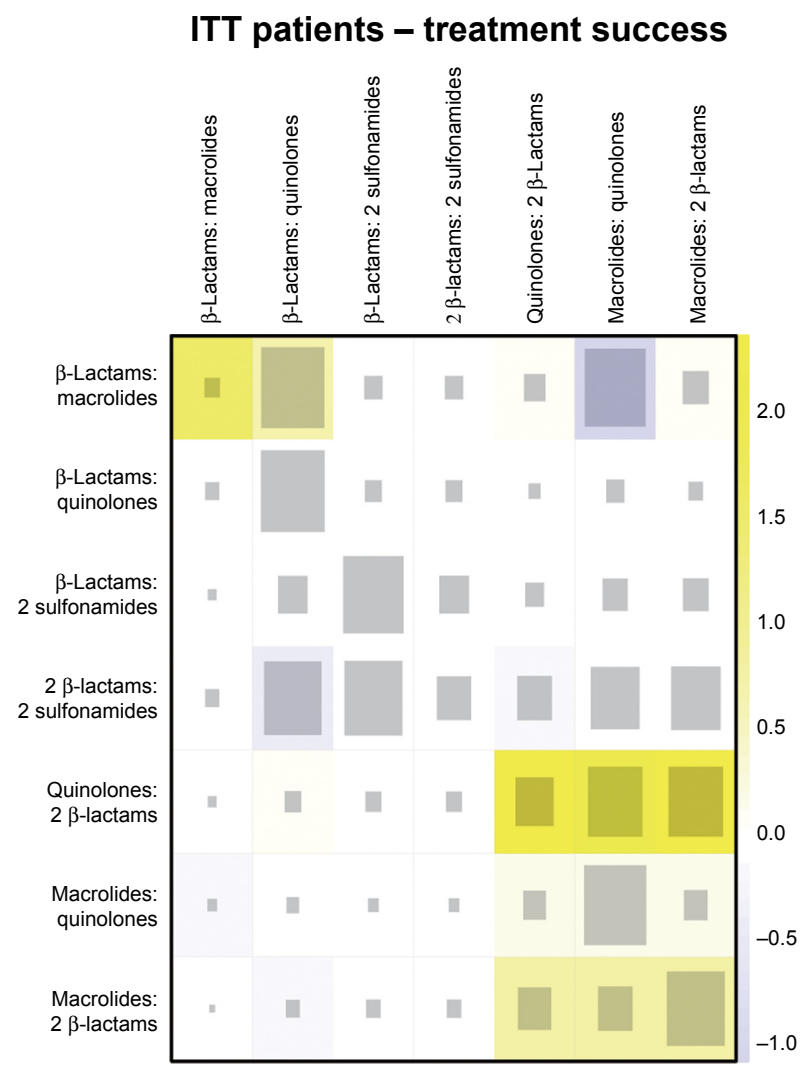

Adverse effects
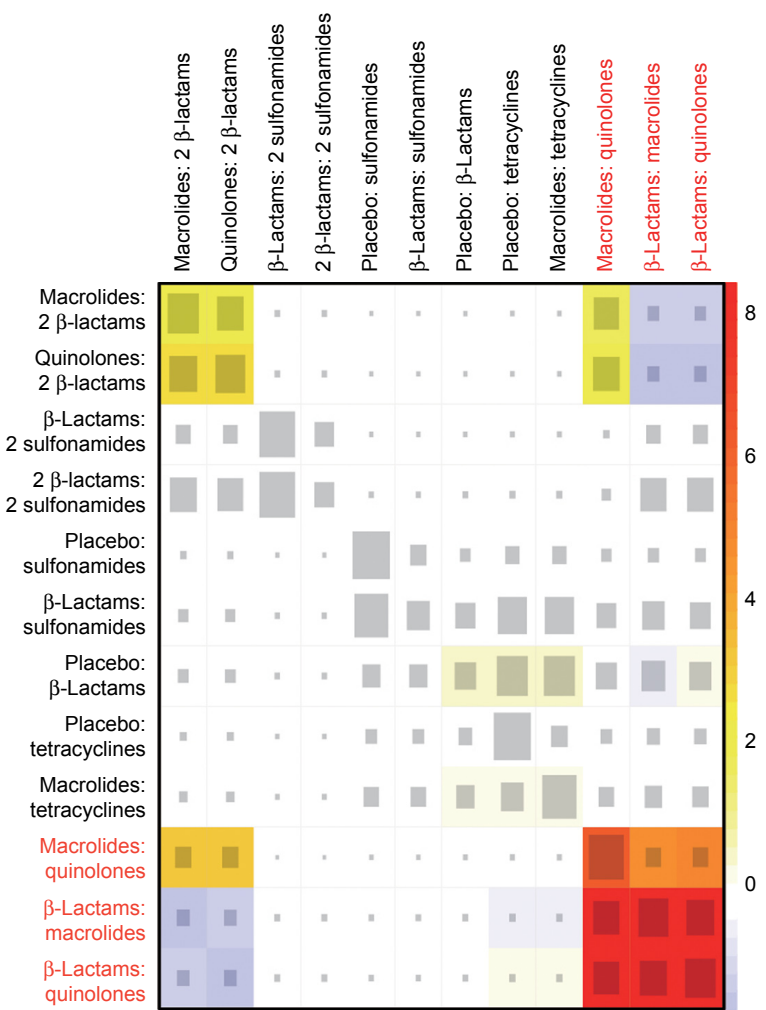

\section{CE patients - treatment success}

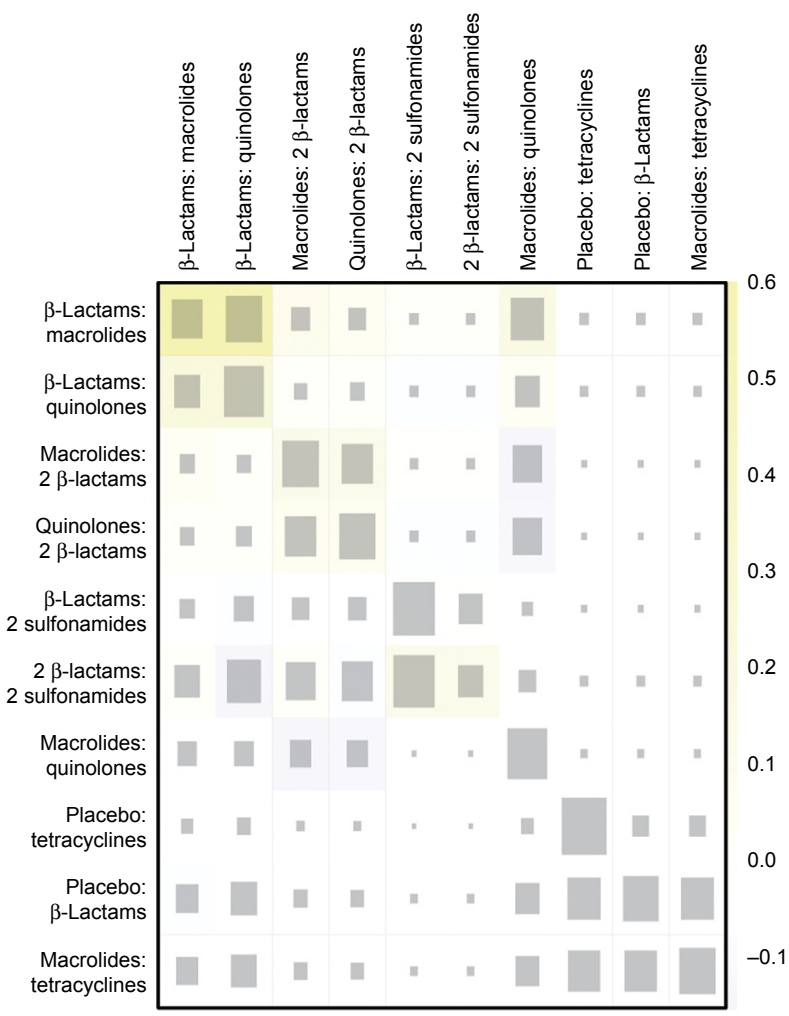

\section{Diarrhea}

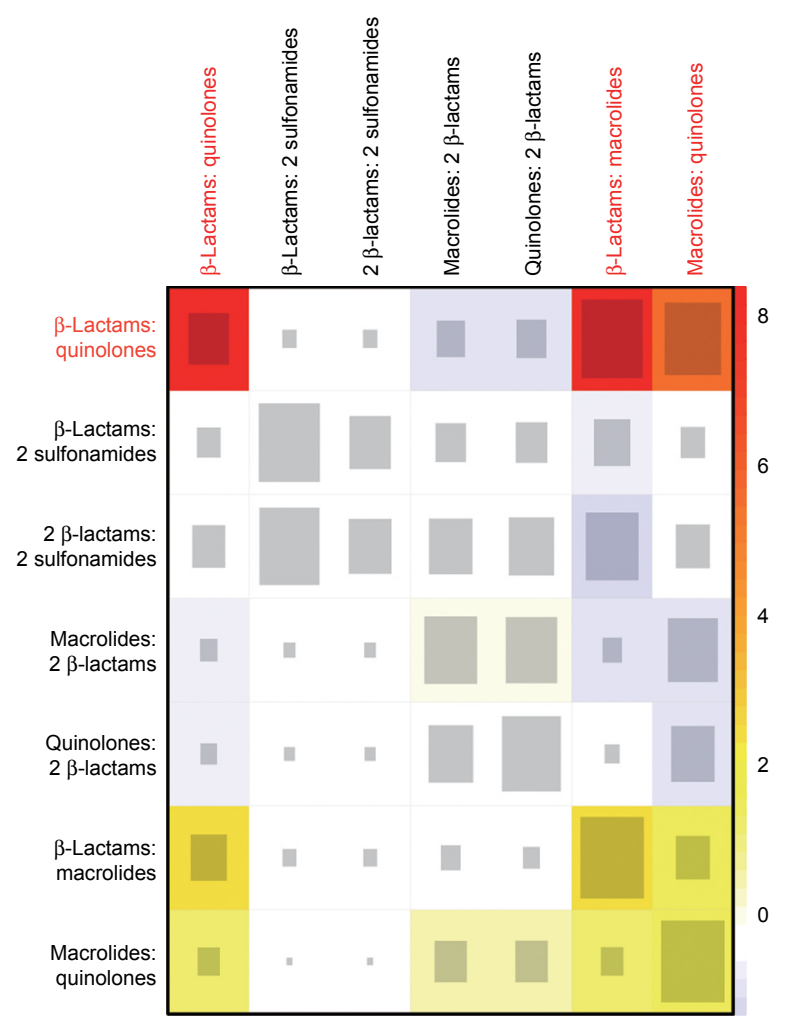

Figure $\mathbf{5}$ Net heat plot. The size of the gray squares indicates the contribution of direct evidence (shown in the column) to the network evidence (shown in the row). The colors are associated with the change in inconsistency between direct and indirect evidence (shown in the row). Blue colors indicate an increase of inconsistency and warm colors indicate a decrease.

Abbreviations: ITT, intention-to-treat; CE, clinically evaluable. 
ITT patients - treatment success

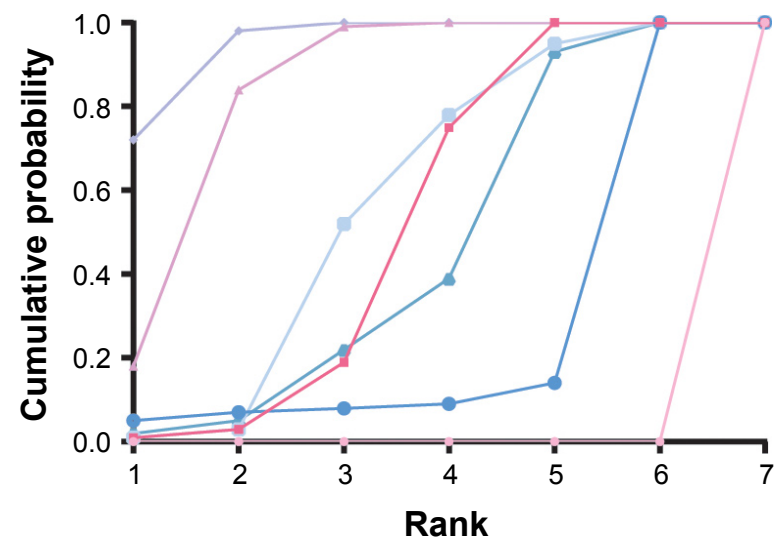

Adverse effects

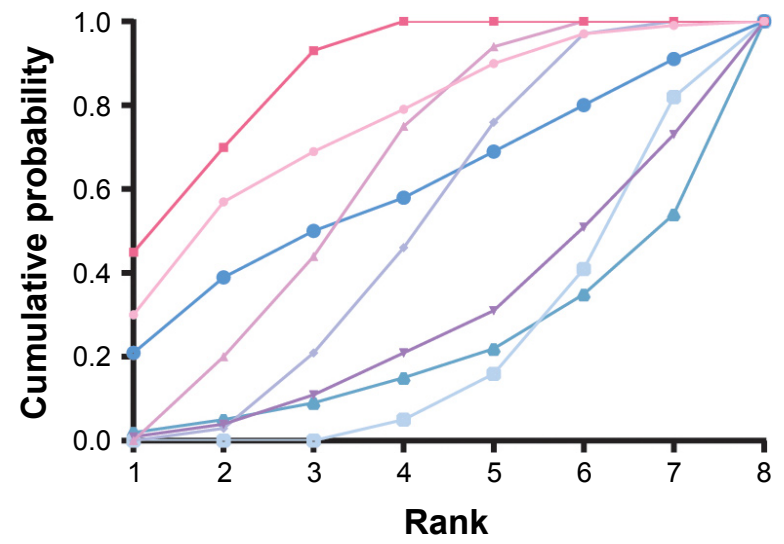

CE patients - treatment success

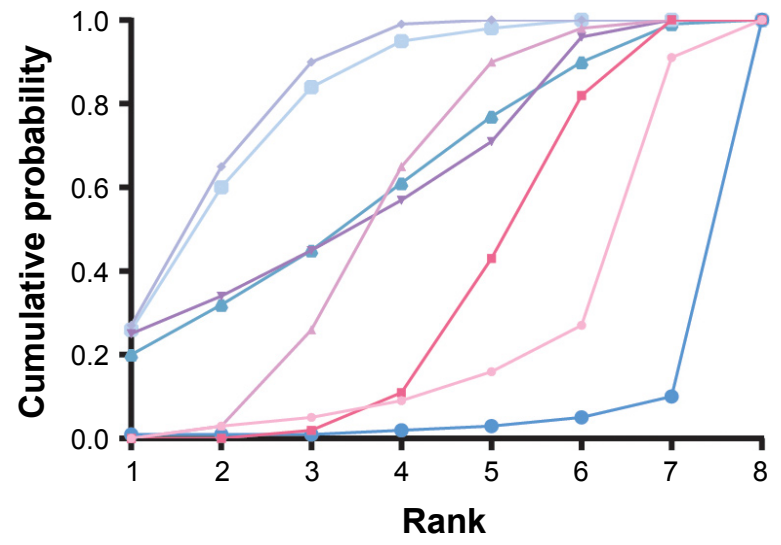

Diarrhea

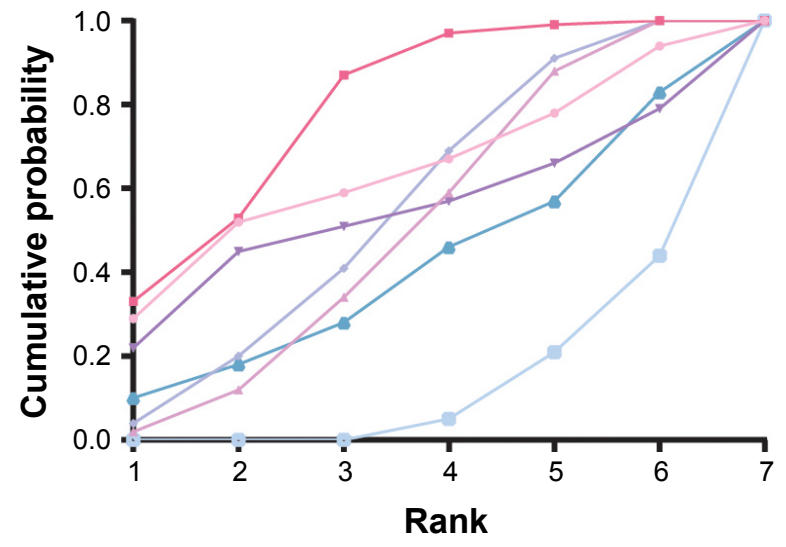

\begin{tabular}{l}
$\rightarrow$ Placebo $\rightarrow$ Macrolides $\rightarrow$ Quinolones \\
$\rightarrow-$-Lactams $\rightarrow$ Tetracyclines $\rightarrow$ Double $\beta$-lactams \\
\hline - Sulfonamides $\rightarrow$ Double sulfonamides
\end{tabular}

Figure 6 SUCRA results.

Abbreviations: ITT, intention-to-treat; CE, clinically evaluable; SUCRA, surface under the cumulative ranking curve.

demonstrated slightly higher efficacy all other treatments apart from quinolones in terms of ITT patient success rate. Double $\beta$-lactams was the second most effective regimen with respect to $\mathrm{CE}$ patient success rate, and there was also evidence suggesting a similar efficacy rate of this antibiotic to double sulfonamides like co-trimoxazole, ${ }^{65}$ which might be due to the small sample size of only 49 as well as the particularly older age of patients (average 62.6 years) involved in the included double sulfonamide research. In addition, the low efficacy of $\beta$-lactams indicated in our study corresponded with other findings, ${ }^{18,25,26}$ and no superiority concerning the efficacy of this treatment was demonstrated.

Table 2 Surface under the cumulative ranking curve (SUCRA) results

\begin{tabular}{lllll}
\hline Treatment & $\begin{array}{l}\text { ITT patients - } \\
\text { treatment success }\end{array}$ & $\begin{array}{l}\text { CE patients - } \\
\text { treatment success }\end{array}$ & $\begin{array}{l}\text { Adverse } \\
\text { effects }\end{array}$ \\
\hline Placebo & $0.001 \%$ & $21.57 \%$ & $74.43 \%$ & Diarrhea \\
$\beta$-Lactams & $49.67 \%$ & $34.00 \%$ & $86.86 \%$ & $63.17 \%$ \\
Macrolides & $83.50 \%$ & $54.57 \%$ & $61.86 \%$ & $78.17 \%$ \\
Tetracyclines & - & $61.14 \%$ & $27.43 \%$ & $49.17 \%$ \\
Quinolones & $95.00 \%$ & $83.00 \%$ & $49.00 \%$ & $53.33 \%$ \\
Sulfonamides & $23.83 \%$ & $3.29 \%$ & $58.29 \%$ & - \\
Double $\beta$-lactams & $54.83 \%$ & $80.43 \%$ & $20.57 \%$ & $11.67 \%$ \\
Double sulfonamides & $43.50 \%$ & $60.57 \%$ & $20.29 \%$ & $40.33 \%$ \\
\hline
\end{tabular}

Abbreviations: ITT, intention-to-treat; CE, clinically evaluable. 

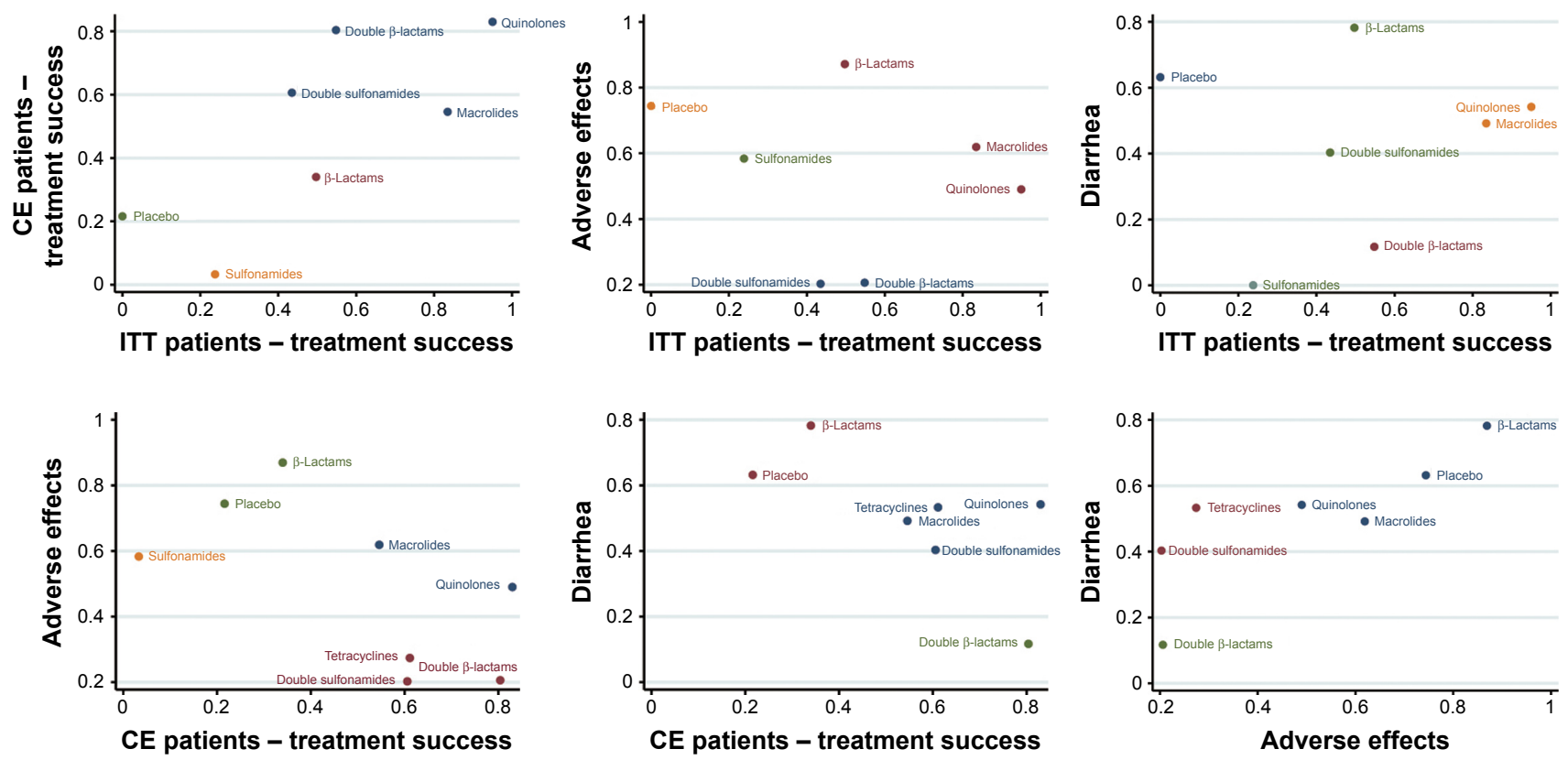

Figure 7 Clustered ranking plot of the network. The plot is based on cluster analysis of SUCRA values. Each plot shows SUCRA values for two outcomes: ITT patient treatment success, CE patient treatment success, adverse effects, and diarhoea. Each color represents a group of treatments which belongs to the same cluster. Treatments lying in the upper right corner are more effective and safer than the other treatments.

Abbreviations: ITT, intention-to-treat; CE, clinically evaluable; SUCRA, surface under the cumulative ranking curve.

More broadly, the MA study carried out by Dimopoulos et $\mathrm{al}^{75}$ on various types of bronchitis-related antibiotics compared the relative efficacy and tolerability of first-line (ie, amoxicillin, trimethoprim/sulfamethoxazole, and doxycycline) and second-line antibiotic regimens (ie, amoxicillin/ clavulanic, macrolides, cephalosporins, and quinolones), concluding that the second-line agents were more potent than the first-line agents, which strongly supported our conclusions.

\section{Secondary outcomes}

Safety or tolerability characteristics were also critical in the process of drug selection analysis. In this NMA, we analyzed all the adverse effects as an aggregate as well as assessed diarrhea as an adverse effect individually. The results indicated that patients receiving double $\beta$-lactams had the highest possibility of experiencing adverse effects including diarrhea compared to all other treatments included. Conversely, the most widely used $\beta$-lactams proved to have the lowest risk of causing side effects.

Discrepancy between direct and indirect evidence was detected in the pairings of quinolones versus $\beta$-lactams, quinolones versus macrolides, and macrolides versus $\beta$-lactams, which might be attributed to the fact that the RCTs included in our study not only used various drugs from the same antibiotic group but also different dosages of the same treatment. Although elements of this issue existed elsewhere, this kind of heterogeneity was more commonly detected in the three groups noted above.

After a careful examination of the results and conclusions of the related studies, we found that the findings from other studies were similar to what we identified concerning secondary outcomes of antibiotics commonly used in the treatment of bronchitis. With respect to the comparison of macrolides versus $\beta$-lactams, one study showed the response rate of common adverse events was $12.8 \%$ versus $11.8 \%$ for diarrhea and $8.9 \%$ versus $3.2 \%$ for nausea in telithromycin and cefuroxime axetil patients, respectively, ${ }^{2}$ showing that macrolides were slightly less tolerable than $\beta$-lactams, which was similar to what this NMA illustrated. Many studies also showed corresponding evidence to our finding that double $\beta$-lactams were associated with a higher risk of inducing drug-related adverse effects on subjects when macrolides were compared to a combination of $\beta$-lactams (such as double $\beta$-lactams). ${ }^{17,42,52,61}$ For example, one study demonstrated that the frequency of adverse effects regarding telithromycin (a type of macrolide) was only half that of amoxicillin/ clavulanate. ${ }^{42}$ However, double sulfonamides, such as cotrimazine, were proven to be well tolerated when treating AECB patients. ${ }^{21}$ This was contradictory to our findings, where this group ranked the second lowest in terms of adverse effects. This inconsistency might be due to the fact that the mentioned study was published in 1984, and the associated 
treating methods, bacterial susceptibility, and patient backgrounds may be quite different from current studies.

Although quinolones and macrolides were recommended as optimal treatments for bronchitis on the basis of the primary outcomes of our NMA, their medium adverse effects including diarrhea lowered their application value. US Centers for Disease Control and Prevention found that patients treated with fluoroquinolones, a type of quinolone, experienced adverse events more often than with macrolides. ${ }^{76}$ With respect to macrolides, their safety was also questioned by one study, which demonstrated that they could lead to debilitating myopathy. ${ }^{77}$ One possible explanation of this could be that some macrolides are potent inhibitors of the cytochrome $\mathrm{P} 450$ system. ${ }^{73}$ The most harmful antibiotic regimen was double $\beta$-lactams, such as amoxicillin/clavulanate and pivampicillin/pivmecillinam. In our study, they were shown to increase the risk of yeast infection and diarrhea and are recommended to be used only within 14 days by the UK Committee on Safety of Medicines. ${ }^{22}$ Our findings with respect to the adverse effects of various antibiotics offered us a systematic review of the relative safety of these treatments for bronchitis, which to some degree offsets the lack of associated wide-range safety comparisons in the current literature.

\section{Strengths and limitations}

Through this research, we obtained an overall understanding of the efficacy as well as safety outcomes from a total of eight groups of interventions including placebo. Unlike the previous individual studies and MAs, this study managed to screen out the favorable treatments for bronchitis pertaining to both CE and ITT success rates and also suggested the drugs with the highest and lowest adverse effects for each. A relatively large sample size and comprehensive antibiotic screening basis (a total of 36 antibiotics belonging to seven groups) added to the reliability and the comprehensiveness of our findings. It should be noted that all of the included studies were RCTs, the outcomes of which are generally expected to be of higher reliability.

Nevertheless, the results of this NMA should be interpreted with the consideration of several limitations. First, we included all three types of bronchitis $(A B, C B$, and AECB) in our study along with subjects of various ages, drugs of different dosages, and durations. All these variables can influence the applicability and feasibility of the ideal intervention. To be more specific, as it has been stated in the introduction that virus is also the cause of bronchitis. Indeed, $\mathrm{AB}$ is primarily caused by viruses ${ }^{78}$ and therefore does not respond to antibiotics while AECB is associated with both bacteria and viruses. ${ }^{79}$ This might lead to efficacy variation in the antibiotics among different subgroups of patients. Thus, a future subgroup NMA might be needed to supplement these results. Another drawback of this study is that bacterial susceptibility has not been taken into account, which also partly influences the efficacy evaluation of antibiotics. Many of the studies are also fairly old (9 before 1990, most of the others between 1990 and 2010, and only one after 2010). As we know, the resistance of bacteria to current antibiotics is highly likely to have changed over these periods, ${ }^{80}$ further affecting the efficacy of antibiotic treatments. As such, a lack of recent RCTs could lower the reliability of the NMA results. In addition, regional variation in resistance might also exist, ${ }^{81}$ which would mean that treatment suggestions may vary among different countries and regions. Stratification by regions is also thus needed in subsequent research.

\section{Prospect}

In this NMA, we included two primary outcomes: ITT patient success rate and $\mathrm{CE}$ patient success rate. As was indicated in our findings, the rankings of antibiotics based on these two types of patients were quite different on the basis of ITT and CE patients' success rate. This inconsistency largely depended on the type of patients involved. In the future, a weighted composition might be applied to combine ITT and CE patient profiles together to form a more inclusive antibiotic recommendation in the treatment of bronchitis.

Studies concerning the antibiotic treatments for bronchitis have often failed to report enough of the adverse effects which appeared during the study. This is a deficiency when considered in contrast to an abundance of efficacy profiles ${ }^{82}$ and could affect the process of screening out an efficacious and safe treatment option. The related discrepancy observed in our NMA also calls for more large-sample RCTs of antibiotic treatments, especially sulfonamides, double sulfonamides, and tetracyclines. Future studies should address these potential problems.

In conclusion, our NMA identified quinolones and macrolides as strong choices in the treatment of ITT bronchitis while quinolones and double $\beta$-lactams performed best in the treatment of $\mathrm{CE}$ bronchitis patients. Double $\beta$-lactams proved to have the highest risk of adverse events while $\beta$-lactams were the least likely to cause adverse effects when prescribed to bronchitis patients. In addition, quinolones and macrolides both showed median adverse effects across all the included 
antibiotics. Thus, considering both treatment success rates and safety profiles, quinolones were recommended as the most preferable treatment option.

\section{Acknowledgments}

We would like to acknowledge the reviewers for their helpful comments on this paper. This research did not receive any specific grant from funding agencies in the public, commercial, or not-for-profit sectors.

\section{Author contributions}

All authors contributed toward data analysis, drafting and critically revising the paper and agree to be accountable for all aspects of the work.

\section{Disclosure}

The authors report no conflicts of interest in this work.

\section{References}

1. Papi A, Bellettato CM, Braccioni F, et al. Infections and airway inflammation in chronic obstructive pulmonary disease severe exacerbations Am J Respir Crit Care Med. 2006;173(10):1114-1121.

2. Zervos MJ, Heyder AM, Leroy B. Oral telithromycin $800 \mathrm{mg}$ once daily for 5 days versus cefuroxime axetil $500 \mathrm{mg}$ twice daily for 10 days in adults with acute exacerbations of chronic bronchitis. J Int Med Res. 2003 31(3):157-169.

3. Mandell GL, Bennett JE, Dolin R. Book Mandell, Douglas and Bennett's Principles and Practice of Infectious Diseases. Volumes 1 and 2. 4th ed. Churchill Livingstone. 1995.

4. Schaberg T, Ballin I, Huchon G, Bassaris H, Hampel B, Reimnitz P. A multinational, multicentre, non-blinded, randomized study of moxifloxacin oral tablets compared with co-amoxiclav oral tablets in the treatment of acute exacerbation of chronic bronchitis. J Int Med Res. 2001; 29(4):314-328.

5. Donaldson GC, Hurst JR, Smith CJ, Hubbard RB, Wedzicha JA. Increased risk of myocardial infarction and stroke following exacerbation of COPD. Chest. 2010;137(5):1091-1097.

6. Soler-Cataluna JJ, Martinez-Garcia MA, Roman Sanchez P, Salcedo E, Navarro M, Ochando R. Severe acute exacerbations and mortality in patients with chronic obstructive pulmonary disease. Thorax. 2005; 60(11):925-931

7. Donaldson GC, Seemungal TA, Bhowmik A, Wedzicha JA. Relationship between exacerbation frequency and lung function decline in chronic obstructive pulmonary disease. Thorax. 2002;57(10):847-852.

8. Kanner RE, Anthonisen NR, Connett JE. Lower respiratory illnesses promote FEV(1) decline in current smokers but not ex-smokers with mild chronic obstructive pulmonary disease: results from the lung health study. Am J Respir Crit Care Med. 2001;164(3):358-364.

9. Seemungal TA, Donaldson GC, Paul EA, Bestall JC, Jeffries DJ, Wedzicha JA. Effect of exacerbation on quality of life in patients with chronic obstructive pulmonary disease. Am J Respir Crit Care Med. 1998;157(5 Pt 1):1418-1422.

10. Anthonisen NR, Manfreda J, Warren CP, Hershfield ES, Harding GK, Nelson NA. Antibiotic therapy in exacerbations of chronic obstructive pulmonary disease. Ann Intern Med. 1987;106(2):196-204.

11. Falagas ME, Avgeri SG, Matthaiou DK, Dimopoulos G, Siempos II. Short- versus long-duration antimicrobial treatment for exacerbations of chronic bronchitis: a meta-analysis. J Antimicrob Chemother. 2008;62(3): 442-450.
12. Zervos M, Martinez FJ, Amsden GW, Rothermel CD, Treadway G. Efficacy and safety of 3-day azithromycin versus 5-day moxifloxacin for the treatment of acute bacterial exacerbations of chronic bronchitis. Int J Antimicrob Agents. 2007;29(1):56-61.

13. Buchanan J, Buchanan WW, Melrose AG, Mc GJ, Price AU. Longterm prophylactic administration of tetracycline to chronic bronchitics. Lancet. 1958;2(7049):719-723.

14. Wilson R, Allegra L, Huchon G, et al. Short-term and long-term outcomes of moxifloxacin compared to standard antibiotic treatment in acute exacerbations of chronic bronchitis. Chest. 2004;125(3):953-964.

15. DeAbate CA, Mathew CP, Warner JH, Heyd A, Church D. The safety and efficacy of short course (5-day) moxifloxacin vs. azithromycin in the treatment of patients with acute exacerbation of chronic bronchitis. Respir Med. 2000;94(11):1029-1037.

16. Chodosh S, DeAbate CA, Haverstock D, Aneiro L, Church D. Shortcourse moxifloxacin therapy for treatment of acute bacterial exacerbations of chronic bronchitis. The Bronchitis Study Group. Respir Med. 2000; 94(1):18-27.

17. Martinot JB, Carr WD, Cullen S, et al. A comparative study of clarithromycin modified release and amoxicillin/clavulanic acid in the treatment of acute exacerbation of chronic bronchitis. Adv Ther. 2001; 18(1):1-11.

18. Johnston RN, Lockhart W, Smith DH, Cadman NK. A trial of phenethicillin in chronic bronchitis. Br Med J. 1961;2(5258):985-986.

19. Wilson R, Schentag JJ, Ball P, Mandell L. A comparison of gemifloxacin and clarithromycin in acute exacerbations of chronic bronchitis and long-term clinical outcomes. Clin Ther. 2002;24(4):639-652.

20. De Vlieger A, Druart M, Puttemans M. Roxithromycin versus doxycycline in the treatment of acute exacerbations of chronic bronchitis. Diagn Microbiol Infect Dis. 1992;15(4 Suppl):123S-127S.

21. Leone G, Lanza R, Paoletti V, Parlapiano C, Vincentelli GM. A clinical trial of co-trimazine (sulfadiazine + trimethoprim) in flare-ups of chronic bronchitis. J Int Med Res. 1984;12(1):1-9.

22. Gillies M, Ranakusuma A, Hoffmann T, et al. Common harms from amoxicillin: a systematic review and meta-analysis of randomized placebo-controlled trials for any indication. CMAJ. 2015;187(1): E21-E31.

23. Bent S, Saint S, Vittinghoff E, Grady D. Antibiotics in acute bronchitis: a meta-analysis. Am J Med. 1999;107(1):62-67.

24. Siempos II, Dimopoulos G, Korbila IP, Manta K, Falagas ME. Macrolides, quinolones and amoxicillin/clavulanate for chronic bronchitis: a meta-analysis. Eur Respir J. 2007;29(6):1127-1137.

25. Liu KX, Xu B, Wang J, et al. Efficacy and safety of moxifloxacin in acute exacerbations of chronic bronchitis and COPD: a systematic review and meta-analysis. $J$ Thorac Dis. 2014;6(3):221-229.

26. Miravitlles M, Molina J, Brosa M. [Clinical efficacy of moxifloxacin in the treatment of exacerbations of chronic bronchitis: a systematic review and meta-analysis]. Arch Bronconeumol. 2007;43(1):22-28.

27. Korbila IP, Manta KG, Siempos II, Dimopoulos G, Falagas ME. Penicillins vs trimethoprim-based regimens for acute bacterial exacerbations of chronic bronchitis: meta-analysis of randomized controlled trials. Can Fam Physician. 2009;55(1):60-67.

28. Zhang L, Wang R, Falagas ME, Chen LA, Liu YN. Gemifloxacin for the treatment of community-acquired pneumonia and acute exacerbation of chronic bronchitis: a meta-analysis of randomized controlled trials. Chin Med J (Engl). 2012;125(4):687-695.

29. Zhu GQ, Zou ZL, Zheng JN, et al. Systematic review and network metaanalysis of randomized controlled trials: comparative effectiveness and safety of direct-acting antiviral agents for treatment-naive hepatitis C genotype 1. Medicine (Baltimore). 2016;95(9):e3004.

30. Zhao BC, Jiang HY, Ma WY, et al. Albendazole and corticosteroids for the treatment of solitary cysticercus granuloma: a network metaanalysis. PLoS Negl Trop Dis. 2016;10(2):e0004418.

31. Zhang MY, Zhu GQ, Shi KQ, et al. Systematic review with network meta-analysis: comparative efficacy of oral nucleos $(t)$ ide analogues for the prevention of chemotherapy-induced hepatitis $\mathrm{B}$ virus reactivation. Oncotarget. 2016;7(21):30642-30658. 
32. Veroniki AA, Straus SE, Ashoor HM, et al. Comparative safety and effectiveness of cognitive enhancers for Alzheimer's dementia: protocol for a systematic review and individual patient data network metaanalysis. BMJ Open. 2016;6(1):e010251.

33. Tvete IF, Natvig B, Gasemyr J, Meland N, Roine M, Klemp M. Correction: comparing effects of biologic agents in treating patients with rheumatoid arthritis: a multiple treatment comparison regression analysis. PLoS One. 2016;11(1):e0146633.

34. Blasi F, Tarsia P, Mantero M, Morlacchi LC, Piffer F. Cefditoren versus levofloxacin in patients with exacerbations of chronic bronchitis: serum inflammatory biomarkers, clinical efficacy, and microbiological eradication. Ther Clin Risk Manag. 2013;9:55-64.

35. Martinez FJ, Grossman RF, Zadeikis N, et al. Patient stratification in the management of acute bacterial exacerbation of chronic bronchitis: the role of levofloxacin $750 \mathrm{mg}$. Eur Respir J. 2005;25(6):1001-1010.

36. Starakis I, Gogos CA, Bassaris H. Five-day moxifloxacin therapy compared with 7-day co-amoxiclav therapy for the treatment of acute exacerbation of chronic bronchitis. Int J Antimicrob Agents. 2004;23(2):129-137.

37. Wilson R, Langan C, Ball $\mathrm{P}$, et al. Oral gemifloxacin once daily for 5 days compared with sequential therapy with i.v. ceftriaxone/oral cefuroxime (maximum of 10 days) in the treatment of hospitalized patients with acute exacerbations of chronic bronchitis. Respiratory Medicine. 2003;97(3):242-249.

38. Soler M, Lode H, Baldwin R, et al. Randomised double-blind comparison of oral gatifloxacin and co-amoxiclav for acute exacerbation of chronic bronchitis. Eur J Clin Microbiol Infect Dis. 2003;22(3):144-150.

39. Amsden GW, Baird IM, Simon S, Treadway G. Efficacy and safety of azithromycin vs levofloxacin in the outpatient treatment of acute bacterial exacerbations of chronic bronchitis. Chest. 2003;123(3):772-777.

40. Weiss LR. Open-label, randomized comparison of the efficacy and tolerability of clarithromycin, levofloxacin, and cefuroxime axetil in the treatment of adults with acute bacterial exacerbations of chronic bronchitis. Clin Ther. 2002;24(9):1414-1425.

41. Grassi C, Casali L, Curti E, Tellarini M, Lazzaro C, Schito G. Efficacy and safety of short course (5-day) moxifloxacin vs 7-day ceftriaxone in the treatment of acute exacerbations of chronic bronchitis (AECB). J Chemother. 2002;14(6):597-608.

42. Aubier M, Aldons PM, Leak A, et al. Telithromycin is as effective as amoxicillin/clavulanate in acute exacerbations of chronic bronchitis. Respir Med. 2002;96(11):862-871.

43. Gotfried MH, DeAbate CA, Fogarty C, Mathew CP, Sokol WN. Comparison of 5-day, short-course gatifloxacin therapy with 7-day gatifloxacin therapy and 10-day clarithromycin therapy for acute exacerbation of chronic bronchitis. Clin Ther. 2001;23(1):97-107.

44. Anzueto A, Fisher CL Jr, Busman T, Olson CA. Comparison of the efficacy of extended-release clarithromycin tablets and amoxicillin/ clavulanate tablets in the treatment of acute exacerbation of chronic bronchitis. Clin Ther. 2001;23(1):72-86.

45. Schouenborg P, Gerdes N, Rasmussen H, Wickers-Nielsen N, Mathiassen E. Azithromycin versus pivampicillin in the treatment of acute exacerbations of chronic bronchitis: a single-blind, doubledummy, multicentre study. J Int Med Res. 2000;28(3):101-110.

46. Kreis. A comparison of moxifloxacin and azithromycin in the treatment of acute exacerbations of chronic bronchitis. J Clin Outcomes Manag. 2000;7(12):33-37.

47. File T, Schlemmer B, Garau J, Lode H, Lynch S, Young C. Gemifloxacin versus amoxicillin/clavulanate in the treatment of acute exacerbations of chronic bronchitis. The 070 Clinical Study group. JChemother. 2000;12(4): 314-325.

48. Wilson R, Kubin R, Ballin I, et al. Five day moxifloxacin therapy compared with 7 day clarithromycin therapy for the treatment of acute exacerbations of chronic bronchitis. J Antimicrob Chemother. 1999;44(4): 501-513.

49. Langan CE, Zuck P, Vogel F, et al. Randomized, double-blind study of short-course (5 day) grepafloxacin versus 10 day clarithromycin in patients with acute bacterial exacerbations of chronic bronchitis. J Antimicrob Chemother. 1999;44(4):515-523.
50. Van Royen P, Betz W, Heyrman J, Taziaux P, Van den Haute M, Poelman M. Dirithromycin versus amoxiclav in the treatment of acute exacerbations of chronic bronchitis. J Int Med Res. 1997;25(1):33-40.

51. Hoepelman IM, Mollers MJ, van Schie MH, et al. A short (3-day) course of azithromycin tablets versus a 10-day course of amoxycillin-clavulanic acid (co-amoxiclav) in the treatment of adults with lower respiratory tract infections and effects on long-term outcome. Int J Antimicrob Agents. 1997;9(3):141-146.

52. Zachariah J. A randomized, comparative study to evaluate the efficacy and tolerability of a 3-day course of azithromycin versus a 10-day course of co-amoxiclav as treatment of adult patients with lower respiratory tract infections. J Antimicrob Chemother. 1996;37(Suppl C): $103-113$.

53. Gris P. Once-daily, 3-day azithromycin versus a three-times-daily, 10-day course of co-amoxiclav in the treatment of adults with lower respiratory tract infections: results of a randomized, double-blind comparative study. J Antimicrob Chemother. 1996;37(Suppl C):93-101.

54. Sachs AP, Koeter GH, Groenier KH, van der Waaij D, Schiphuis J, Meyboom-de Jong B. Changes in symptoms, peak expiratory flow, and sputum flora during treatment with antibiotics of exacerbations in patients with chronic obstructive pulmonary disease in general practice. Thorax. 1995;50(7):758-763.

55. Beghi G, Berni F, Carratu L, et al. Efficacy and tolerability of azithromycin versus amoxicillin/clavulanic acid in acute purulent exacerbation of chronic bronchitis. J Chemother. 1995;7(2):146-152.

56. Verheij TJ, Hermans J, Mulder JD. Effects of doxycycline in patients with acute cough and purulent sputum: a double blind placebo controlled trial. Br J Gen Pract. 1994;44(386):400-404.

57. Ulmer W. Fleroxacin versus amoxicillin in the treatment of acute exacerbation of chronic bronchitis. Am J Med. 1993;94(3A):136S-141S.

58. Chodosh $\mathrm{S}$. Efficacy of fleroxacin versus amoxicillin in acute exacerbations of chronic bronchitis. Am J Med. 1993;94(3A):131S-135S.

59. Mertens JC, van Barneveld PW, Asin HR, et al. Double-blind randomized study comparing the efficacies and safeties of a short (3-day) course of azithromycin and a 5-day course of amoxicillin in patients with acute exacerbations of chronic bronchitis. Antimicrob Agents Chemother. 1992;36(7):1456-1459.

60. Guay DR, Craft JC. Comparative safety and efficacy of clarithromycin and ampicillin in the treatment of out-patients with acute bacterial exacerbation of chronic bronchitis. J Intern Med. 1992;231(3):295-301.

61. Dautzenberg B, Scheimberg A, Brambilla C, et al. Comparison of two oral antibiotics, roxithromycin and amoxicillin plus clavulanic acid, in lower respiratory tract infections. Diagn Microbiol Infect Dis. 1992;15(4 Suppl):85S-89S.

62. Bachand RT Jr. Comparative study of clarithromycin and ampicillin in the treatment of patients with acute bacterial exacerbations of chronic bronchitis. J Antimicrob Chemother. 1991;27(Suppl A):91-100.

63. Aldons PM. A comparison of clarithromycin with ampicillin in the treatment of outpatients with acute bacterial exacerbation of chronic bronchitis. J Antimicrob Chemother. 1991;27(Suppl A):101-108.

64. Gove RI, Cayton RM. A double-blind comparison of amoxycillin with trimethoprim in acute exacerbations of chronic bronchitis. J Antimicrob Chemother. 1985;15(4):495-499.

65. Lal S, McGhie D, Kerfoot P. A comparison of pivmecillinam/pivampicillin and co-trimoxazole in hospitalized patients with acute exacerbations of chronic bronchitis. J Antimicrob Chemother. 1984;14(2):179-184.

66. Anderson G, Williams L, Pardoe T, Peel ET. Co-trimoxazole versus cefaclor in acute on chronic bronchitis. J Antimicrob Chemother. 1981; 8(6):487-489.

67. Davies D, Darke CS. Sulfametopyrazine prophylaxis in chronic bronchitis. Br J Dis Chest. 1978;72(3):231-234.

68. Pines A, Nandi AR, Raafat H, Rahman M. Amoxycillin and co-trimoxazole in acute purulent exacerbations of chronic bronchitis. Chemotherapy. 1977;23(1):58-64.

69. Stott NC, West RR. Randomised controlled trial of antibiotics in patients with cough and purulent sputum. Br Med J. 1976;2(6035): $556-559$. 
70. Heeb S, Fletcher MP, Chhabra SR, Diggle SP, Williams P, Camara M. Quinolones: from antibiotics to autoinducers. FEMS Microbiol Rev. 2011;35(2):247-274.

71. Ivanov DV, Budanov SV. [Ciprofloxacin and antibacterial therapy of respiratory tract infections]. Antibiot Khimioter. 2006;51(5):29-37.

72. Hooper DC. Emerging mechanisms of fluoroquinolone resistance. Emerg Infect Dis. 2001;7(2):337-341.

73. Tenson T, Lovmar M, Ehrenberg M. The mechanism of action of macrolides, lincosamides and streptogramin B reveals the nascent peptide exit path in the ribosome. J Mol Biol. 2003;330(5):1005-1014.

74. Drainas D, Kalpaxis DL, Coutsogeorgopoulos C. Inhibition of ribosomal peptidyltransferase by chloramphenicol. Kinetic studies. Eur J Biochem. 1987;164(1):53-58.

75. Dimopoulos G, Siempos II, Korbila IP, Manta KG, Falagas ME. Comparison of first-line with second-line antibiotics for acute exacerbations of chronic bronchitis: a metaanalysis of randomized controlled trials. Chest. 2007;132(2):447-455.

76. Shehab N, Patel PR, Srinivasan A, Budnitz DS. Emergency department visits for antibiotic-associated adverse events. Clin Infect Dis. 2008; 47(6):735-743.
77. Sathasivam S, Lecky B. Statin induced myopathy. BMJ. 2008; 337:a2286.

78. Albert RH. Diagnosis and treatment of acute bronchitis. Am Fam Physician. 2010;82(11):1345-1350.

79. Brunton S, Carmichael BP, Colgan R, et al. Acute exacerbation of chronic bronchitis: a primary care consensus guideline. Am J Manag Care. 2004;10(10):689.

80. Livermore DM. Fourteen years in resistance. Int J Antimicrob Agents. 2012;39(4):283-294.

81. Andrade SSD, Gales AC, Sader HS. Antimicrobial resistance in gram-negative bacteria from developing countries. In: Sosa A de J, Byarugaba DK, Amabile C, Hsueh PR, Kariuki S, Okeke IN, editors. Antimicrobial Resistance in Developing Countries. New York: SpringerVerlag; 2010:249-266.

82. Loke YK, Price D, Herxheimer A. Systematic reviews of adverse effects: framework for a structured approach. BMC Med Res Methodol. 2007;7:32.
International Journal of COPD

\section{Publish your work in this journal}

The International Journal of COPD is an international, peer-reviewed journal of therapeutics and pharmacology focusing on concise rapid reporting of clinical studies and reviews in COPD. Special focus is given to the pathophysiological processes underlying the disease, intervention programs, patient focused education, and self management protocols.

\section{Dovepress}

This journal is indexed on PubMed Central, MedLine and CAS. The manuscript management system is completely online and includes a very quick and fair peer-review system, which is all easy to use. Visit http://www.dovepress.com/testimonials.php to read real quotes from published authors.

Submit your manuscript here: http://www.dovepress.com/international-journal-of-chronic-obstructive-pulmonary-disease-journal 